Journal of Engineering Science and Technology Review 7 (5) (2014) 24-28

Special Issue on Simulation of Manufacturing Technologies
JOURNAL OF

Engineering Science and

Technology Review

Conference Article

\title{
A 2D Computer Model of Cutting of the A2024 Aluminum Alloy
}

\author{
G.R. Khalikova ${ }^{1}$, A.T. Bikmeyev*¹, R.K. Gazizov ${ }^{1}$ and A. Vairis ${ }^{2}$ \\ ${ }^{1}$ Ufa State Aviation Technical University, Ufa, Russian Federation \\ ${ }^{2}$ Dpt. of Mechanical Engineering, Technological Educational Institute of Crete, Heraklion 71004, Greece
}

Received 15 September 2014; Accepted 29 September 2014

\begin{abstract}
Machining can have a significant effect on the properties of machined parts of different equipment during their production. This paper is on the effect of vertical angle and cutting speed on temperature and stress. Using computer modeling values of these parameters were identified. Using the least squares method and a factorial computer experiment the dependence of peak values of temperature and stress is shown.
\end{abstract}

Keywords: machining, least square method, Transvalor FORGE, A2024

\section{Introduction}

The machining process of industrial alloys is a one of the most important manufacturing processes among the whole range of parts manufacturing of modern machinery. The process indeed often forms the final microstructure and internal stress and strain fields especially near the surface.

Most papers on modeling of machining focus on the wear of tool and the chip formation. They have data on [1-4]: evolution of the cutting force, von Misses stress, forming parameters of chips among other. The study of the properties of cut samples, their formation and evolution have not been studied yet.

In these days improved materials with ultrafine microstructures are being used in industry increasingly. It is It is very important to keep the microstructure of these materials and their unique features during manufacturing. And it is well known, that big values of strains and temperature might result in recrystalization processes. Tool angle and its speed have great effect on these characteristics [5]. Thus requirements arise for the process parameters, where, for example, temperature should not exceed a maximum value, as it grains will grow.

This paper is on numerical modeling of cutting A2024 aluminum alloy. The Transvalor FORGE package was used. The effects of cutting speed and cutting tool angle on temperature, stress and strain were studied.

\section{Computer model}

The computer model developed is shown in Fig.1.The sample has a rectangular cross section with dimensions 14.5 $\mathrm{x} 14 \mathrm{~mm}$, which is cut to a depth of cut of $0.5 \mathrm{~mm}$. The cutting tool moves with a constant speed along the horizontal axis parallel to the surface of the sample. The

* E-mail address: bikmeyev-at@ugatu.su ISSN: 1791-2377 @ 2014 Kavala Institute of Technology. All rights reserved. bottom edge of the sample is fixed in space. The effect of friction is neglected. The heat exchange between sample and the cutting tool and between the sample and the environment is neglected too. The Table 1 lists the material properties of the sample.

Preliminary calculations showed that in the area of cutting the element size should be at least twice smaller than the depth of cut. Therefore the finite element mesh contains five areas with different size of elements (from top to bottom):

- $\quad$ edge size $0.1 \mathrm{~mm}$.

- $\quad$ edge size $0.25 \mathrm{~mm}$.

- $\quad$ edge size $0.5 \mathrm{~mm}$.

- $\quad$ edge size $1 \mathrm{~mm}$.

- $\quad$ edge size $2 \mathrm{~mm}$.

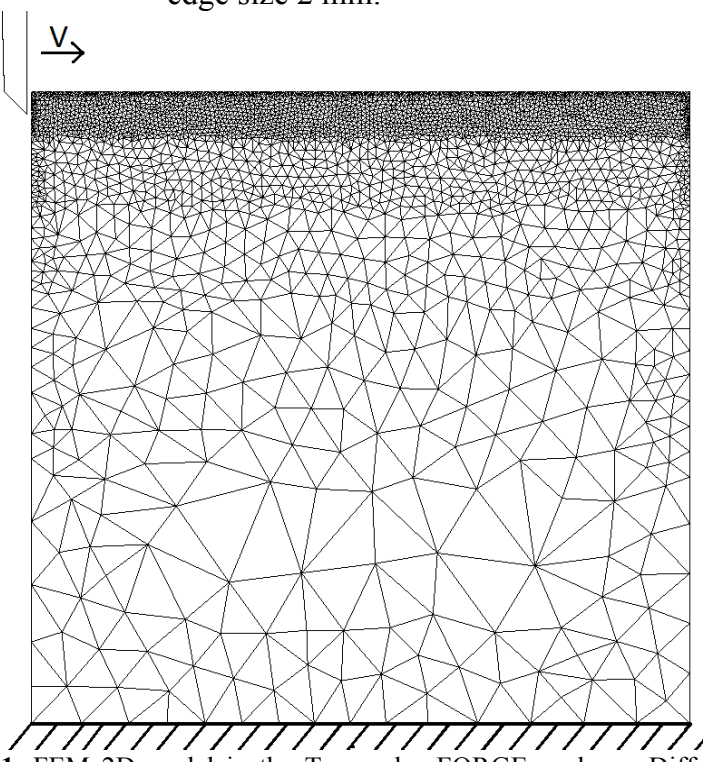

Fig. 1. FEM 2D-model in the Transvalor FORGE package. Different mesh zones and direction of cutting tool movement are shown. 
Table 1. Material properties

\begin{tabular}{l|l}
\hline Parameter & Value \\
\hline Density, $\rho\left(\mathrm{kg} / \mathrm{m}^{3}\right)$ & 2800 \\
\hline Young modulus, E $(\mathrm{GPa})$ & 73 \\
\hline Poisson coefficient, $\nu$ & 0.3 \\
\hline Heat capacity, $c_{\mathrm{p}}\left(\mathrm{J} / \mathrm{kg}{ }^{\circ} \mathrm{C}\right)$ & 1230 \\
\hline $\begin{array}{l}\text { Thermal conductivity, } \\
\lambda\left(\mathrm{W} / \mathrm{m}^{\circ} \mathrm{C}\right)\end{array}$ & 250 \\
\hline$T_{\text {room }}\left({ }^{\circ} \mathrm{C}\right)$ & 20 \\
\hline
\end{tabular}

There were two sets of values of the cutting speed and vertical angle (see Fig.2 for explanation) selected to investigate their effect on the temperature field and stress distribution in the sample. The values are:

- cutting speed (m/s): 0.1, 0.3, 0.5, 0.8, 1, 1.5;

- cutting tool vertical angle (degrees): $0^{\circ}, \pm 3^{\circ}, \pm 5^{\circ}, 20^{\circ}$, $40^{\circ}$.

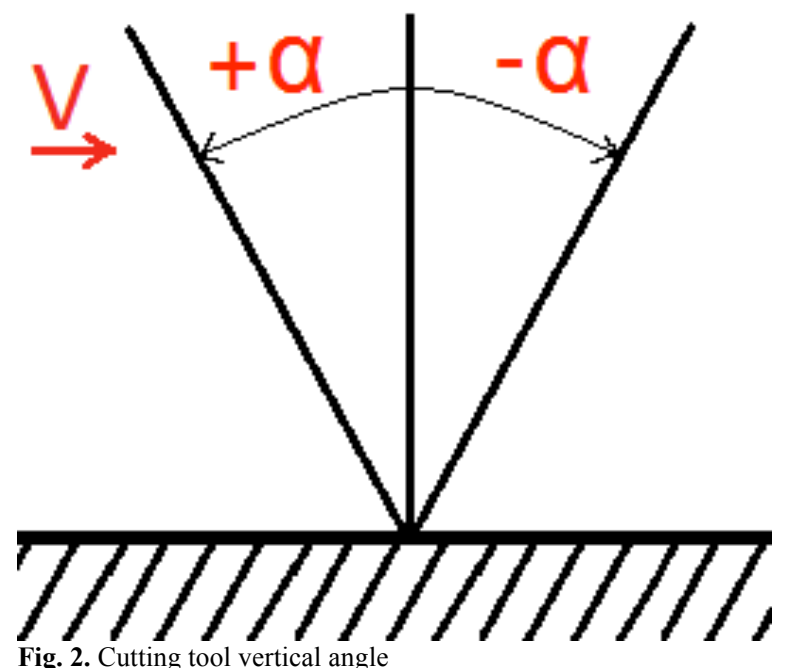

All analyses were performed with Transvalor FORGE 2011 package. Calculations were stopped when the cutting tool reached an offset of $12.7 \mathrm{~mm}$ from the start. This decision was made to avoid distortions from the catastrophic destruction of the material on the right edge of the sample, especially during high values of cutting speed.

\section{Effect of the cutting speed}

Figure 3 compares the temperature field for the lowest and largest cutting speed at an angle $0^{\circ}$. It can be seen that increasing the cutting speed increases the temperature of chips too. For low speed the temperature field has an ellipsoid form and penetrates deeply in the sample. In case of large speeds the maximum temperature is located near surface and temperature has a more flat and elongated form.

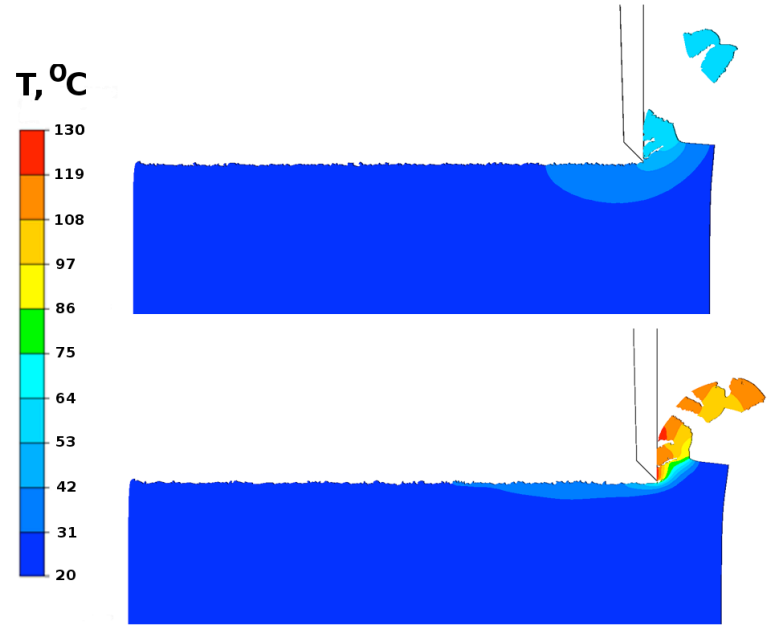

Fig. 3. Temperature in the sample for a cutting tool angle $\alpha=0^{\circ}$, and cutting speed $0.1 \mathrm{~m} / \mathrm{s}$ (top) and $1.5 \mathrm{~m} / \mathrm{s}$ (bottom).

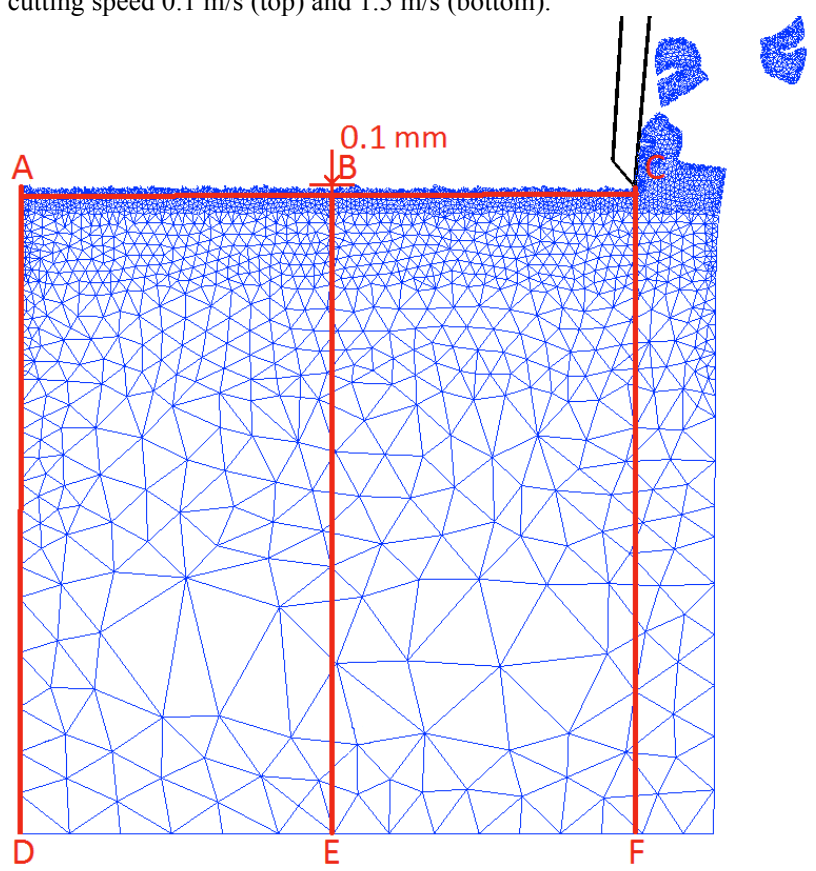

Fig. 4. Study lines to plot temperature and stress.

Figure 5 shows depicts temperature along $\mathrm{AC}$ (see Fig.4), which is located at a distance of $0.1 \mathrm{~mm}$ away from the freshly cut surface, when the cutting tool stops. Close to the cut zone temperature increases. As cutting speed increases peak temperature in it increases as well. It can also be seen, that for high values of speed (greater than $0.5 \mathrm{~m} / \mathrm{s}$ ) peak temperature rises slowly, which may indicate reaching a plateau of peak temperature $[4,6]$. The plots show the same temperature far away from the cutting zone, due to heat transfer into the rest of the sample. The temperature for the highest speed has non-monotonic character because of the increased material damage in the cutting zone [4]. During cutting pieces of material can break off and surface notches and burrs can form. 


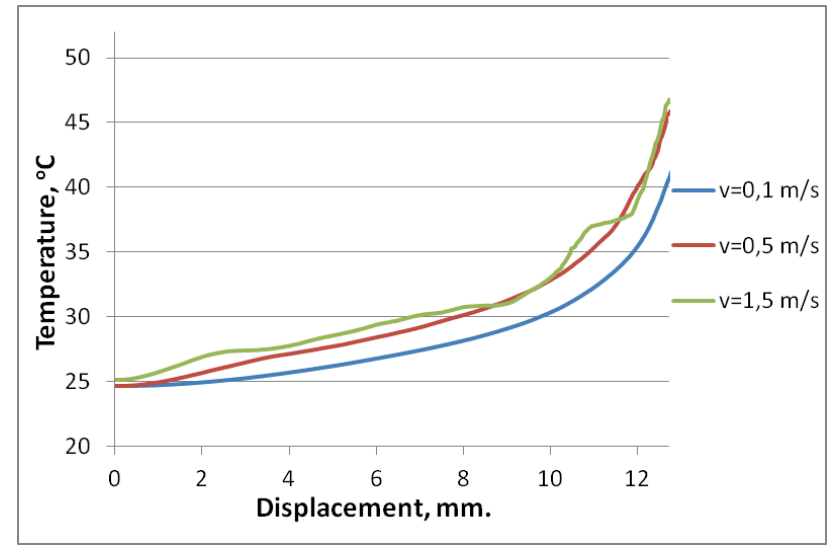

Fig. 5. Temperature along line AC for different values of cutting speed.

From a development point of view it is very important to know the depth of heating of the sample and the maximum temperature reached inside the sample. Figure 6 shows temperature along $\mathrm{AD}, \mathrm{BE}$ and $\mathrm{CF}$ (see Fig.4) for different values of cutting speed. It can be seen, that far depth of heat penetration has evident dependence on the speed value. The temperature of the whole sample increases by 3-5 degrees and is relatively uniform far away from the cutting zone. Closer to the cutting zone, a layer of 1-2 mm width shows increased temperature at a steep gradients, which is very important.

High temperatures and steep gradients produce large residual stresses. When machining materials with an ultrafine structure this can increase grain size and eliminate the ultrafine structure. These changes can take place only close to the cut surface within a depth of 1-2 mm, while surface defects often cause destruction of parts, which requires the selection of parameters that will provide good surface quality and keep the original microstructure.
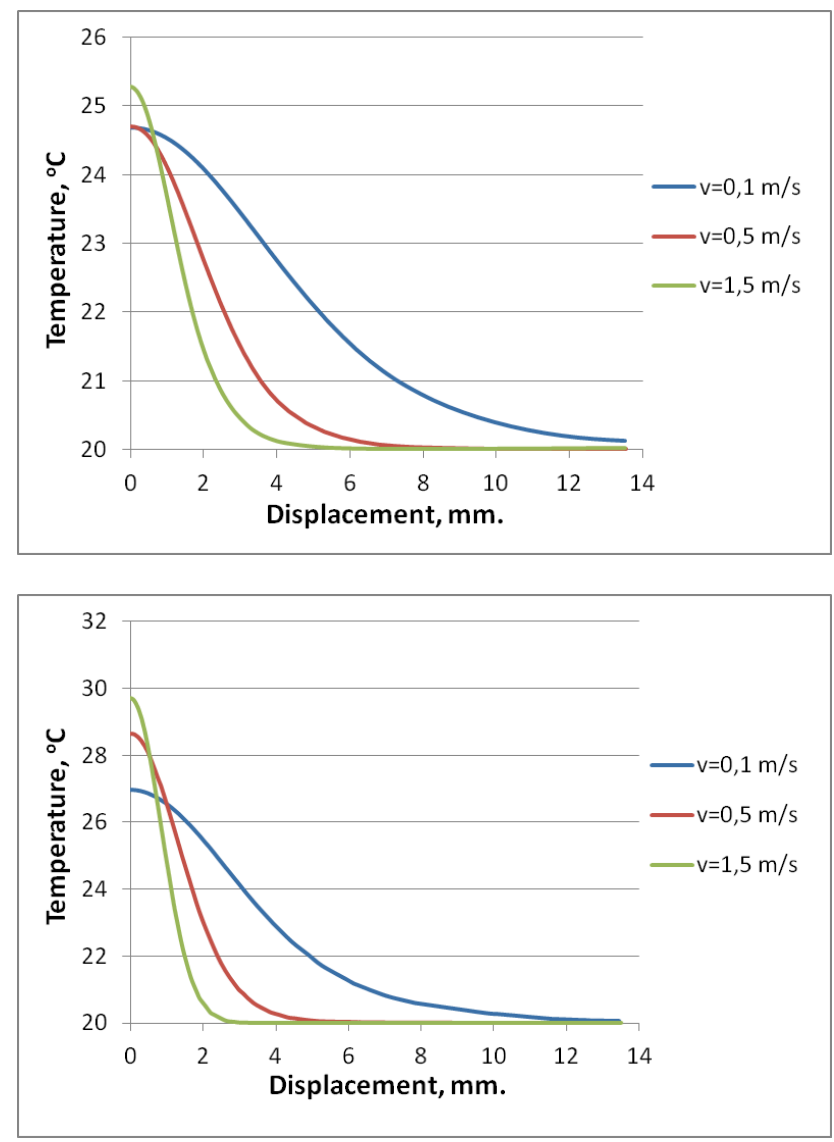

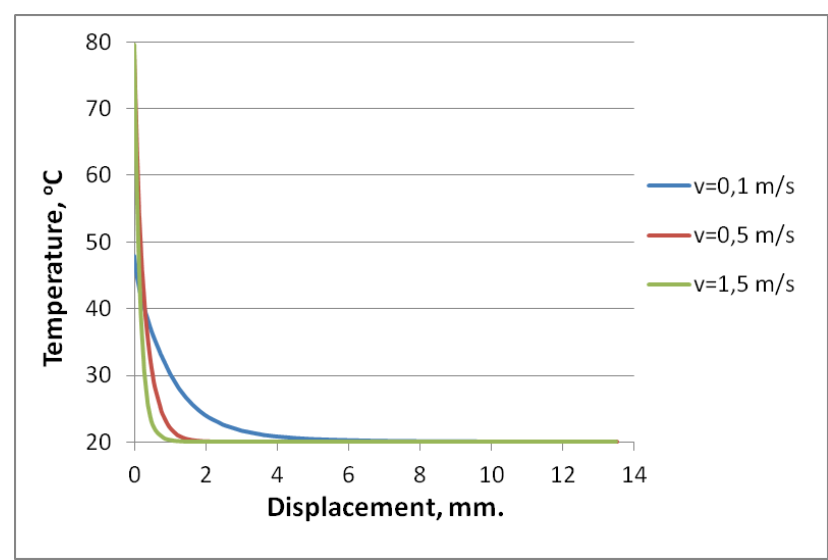

Fig. 6. Temperature along $\mathrm{AD}$ (top), BE (middle), CF (bottom) for different cutting speeds.

Figure 7 shows the stresses close to the cut surface for different cutting speeds. The maximum stress increases with cutting speed, but is not as pronounced as with temperature. On the other hand residual stresses do not depend on speed. High values of temperature and stress close to the cutting zone might result in dynamic recrystallization. Then value of the cutting speed has great effect on temperature distribution in the sample and on peak values of stresses and temperature in a cutting zone.

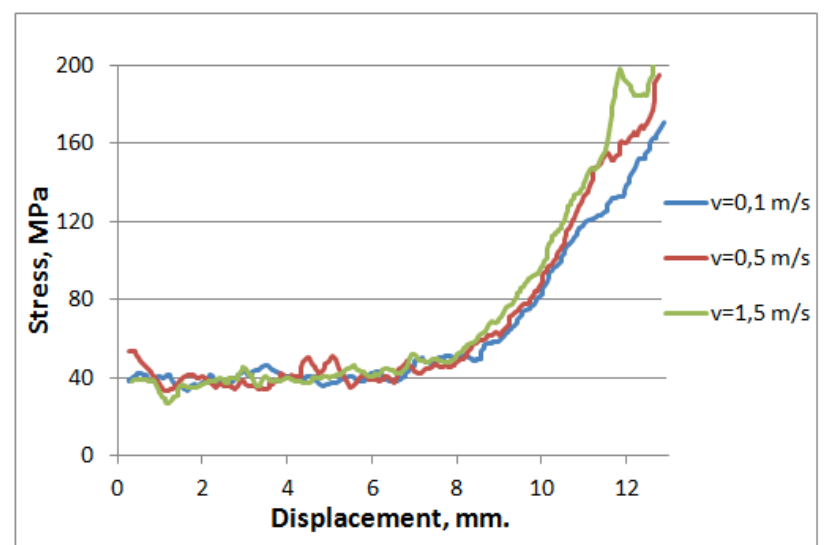

Fig. 7. Stress distribution along AC (see Fig.3) for different cutting speeds.

\section{Effect of the cutting tool vertical angle}

Another important parameter is the vertical angle of the cutting tool. All previous analyses were performed for a cutting tool at a vertical angle $0^{\circ}$. The following analyses we performed for a constant speed at different vertical angles of cutting tool.

In Fig. 8 it can be seen from the lowest and highest cutting speed that an increase in cutting speed produces non uniform heating of the sample and cut surface. Increasing the vertical angle decreases maximum temperature at the cutting zone and the average temperature in a sample. This effect holds for both slow and fast cutting speeds. 

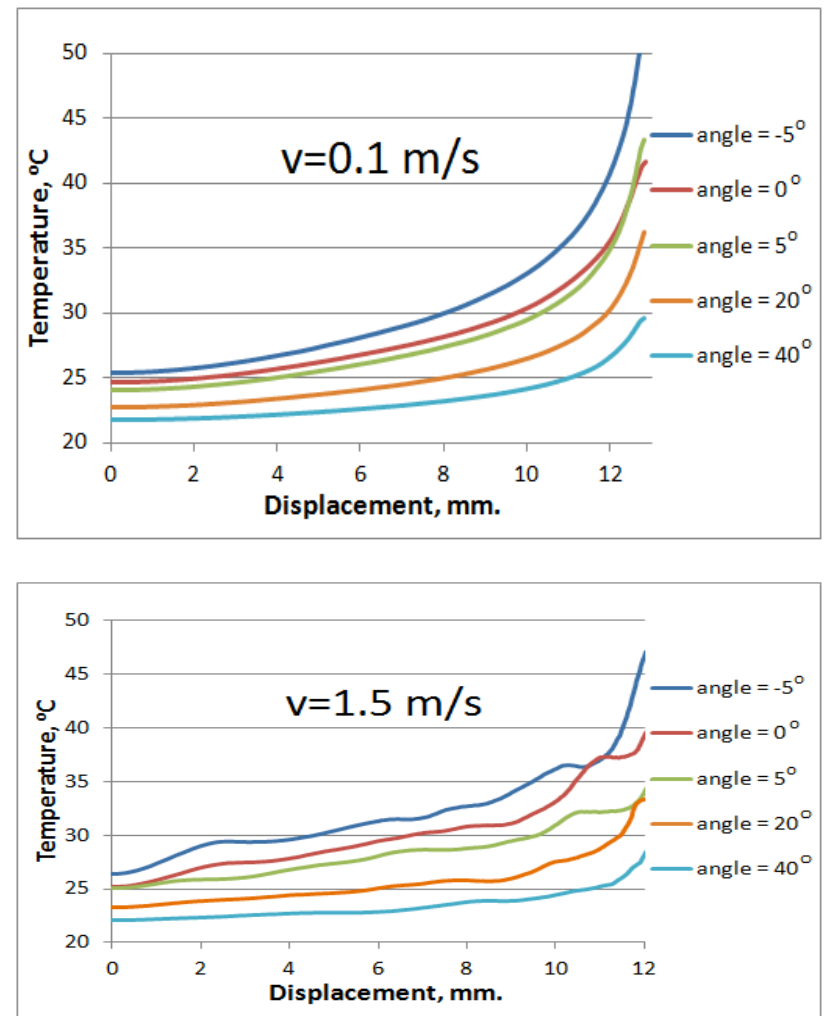

Fig. 8. Temperature along AC (see Fig.3) for different vertical angles of the cutting tool.

For slow cutting speeds (Fig.9) increasing the cutting tool angle increases stress levels, but for fast cutting speeds stress distribution shows the opposite behavior: where increasing the vertical angle decreases the maximum stress. For both cases changes in the vertical angle has a negligible effect on residual stresses.
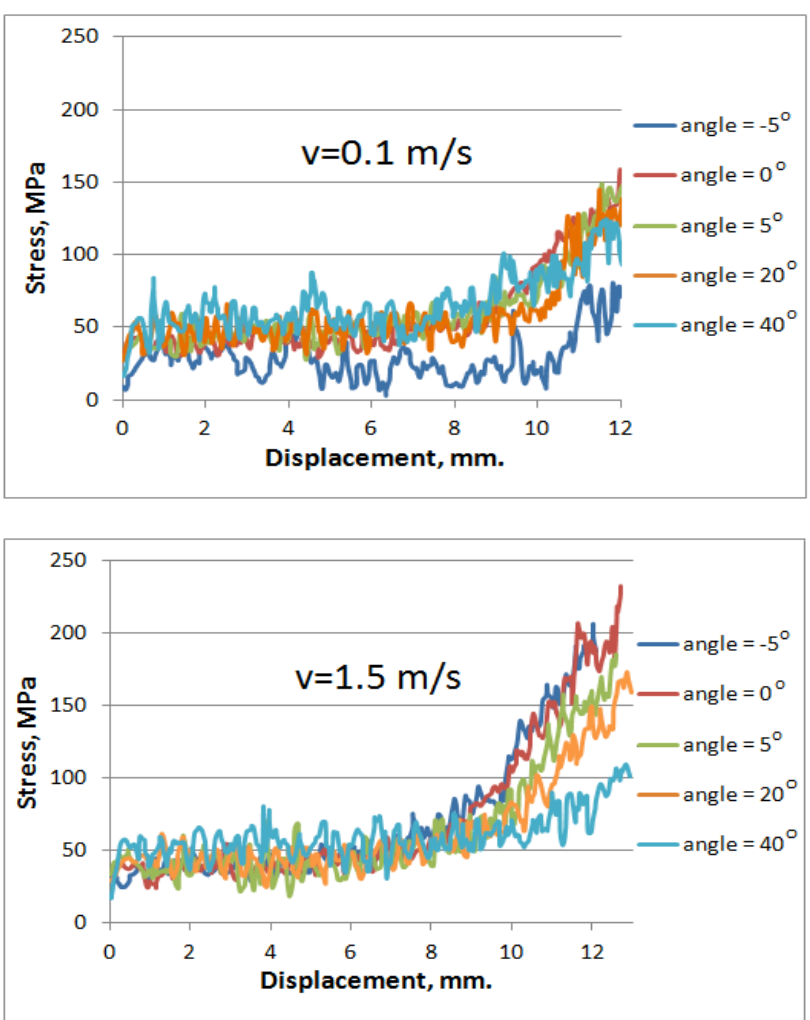

Fig. 9. Stress along AC (see Fig.3) for different vertical angles of the cutting tool.

\section{Factorial experiment}

There is no discernible effect of the cutting parameters on stress and temperature. The employment of a factorial experiment will allow building a mathematical expression for the relationship of peak stress and temperature with cutting speed and vertical angle.

If a linear form of dependence is assumed, then functions will be:

$[\sigma, T]=b_{0}+b_{1} v+b_{2} \alpha+b_{12} v a$

where $v$ - the cutting speed, $\alpha$ - the vertical angle of cutting tool.

Table 2 contains values of factors' levels for $3^{k}$ factorial experiments. A total of 9 simulations will be required.

Table 2. Values of factors

\begin{tabular}{c|c|c}
\hline Level & $\begin{array}{c}\text { Cutting } \\
\text { Speed, m/s }\end{array}$ & $\begin{array}{c}\text { Vertical } \\
\text { Angle, } \\
\text { degrees }\end{array}$ \\
\cline { 2 - 3 } & $v$ & $\alpha$ \\
\hline High & 1.5 & 40 \\
Middle & 0.8 & 20 \\
Small & 0.1 & 0 \\
\hline
\end{tabular}

In order to simplify factors will be normalized as follows:

$[v, \alpha]=\frac{\overline{[v, \alpha]}-\overline{[v, \alpha]}]_{0}}{I_{[v, \alpha]}}$

where $[v, \alpha]-$ a value of a factor in the new variables, $\overline{[v, \alpha]}$ - original value of factor, $\overline{[v, \alpha]}]_{0}$ - original value of factor for the base level, $I_{[v, \alpha]}-$ interval of variety. The factorial experiment matrix is shown in Table 3.

Table 3. Factorial experiment matrix

\begin{tabular}{c|c|c|c|c}
\hline Number & $\mathbf{v}$ & $\boldsymbol{\alpha}$ & $\boldsymbol{\sigma}, \mathbf{M P a}$ & $\mathbf{T},{ }^{\circ} \mathbf{C}$ \\
\hline 1 & -1 & -1 & 64.07 & 62.84 \\
2 & -1 & 0 & 62.99 & 52.86 \\
3 & -1 & 1 & 59.67 & 42.04 \\
4 & 0 & -1 & 62.85 & 114.62 \\
5 & 0 & 0 & 59.78 & 85.90 \\
6 & 0 & 1 & 54.17 & 60.32 \\
7 & 1 & -1 & 73.03 & 125.15 \\
8 & 1 & 0 & 64.57 & 94.20 \\
9 & 1 & 1 & 59.96 & 66.71 \\
\hline
\end{tabular}

To find coefficients of Eq. 1 the least squares method was used:

$U=\sum_{i=1}^{9}\left([\sigma, T]_{i}-[\sigma, T]\left(v_{i}, \alpha_{i}\right)\right)^{2} \rightarrow \min$

And the following functions for temperature and stress were identified with cutting speed and cutting tool vertical angle as variables:

$$
\begin{aligned}
& T=-17.11 v \alpha+26.34 v-28.82 \alpha+72.06 \\
& \sigma=-8.87 v \alpha+4.81 v-11.63 \alpha+65.03
\end{aligned}
$$


As all factors in Eq.2 are normalized, then the effect of cutting parameters is determined by the coefficient in multiplications. From analysis of Eq.2 it follows, that the strongest effect on peak stress and temperature is from the vertical angle of the cutting tool and its increase reduces stress and temperature. For fast cutting speeds $(v>1 \mathrm{~m} / \mathrm{s})$ the associated effect of speed and angle becomes pronounced.

\section{Conclusions}

A 2D numerical model of cutting was developed. From the calculations of the analyses the following conclusions have been reached:

- Increasing cutting speed affects proportionally temperature near the cut surface and its maximum value.

- Increasing the vertical angle of the cutting tool decreases temperature, with this effect being stronger than that of cutting speed.

- For slow cutting speeds peak stress increases with increasing the vertical angle of the cutting tool. For high values of speed $(v>1 \mathrm{~m} / \mathrm{s})$ stress decreases with increasing the vertical angle of the cutting tool.

Thus the orientation and speed of the cutting tool has a great effect on the final characteristics of the volume of the material close to the surface. Results of the factorial experiment can be used to determine the optimum parameters of the cutting process and avoid overheating or overstressing the parts.

\section{Acknowledgments}

This work was produced during the joint project between USATU (Ufa State Aviation Technical University) and UMPO (Ufa Engine Industrial Association) with title "Elaboration and industrial development of high-precision shaping coordinated technologies and superficial hardening of responsible details from Al-alloys with heightened constructional energy efficiency", implemented under the contract №40/10-30976 sponsored by the Ministry of Education and Science of the Russian Federation (contract №02.G25.31.0010 between UMPO and the Ministry of Education and Science of the Russian Federation) through the Resolution of the Russian Federation Government № 218 from April 9, 2010.

\section{References}

[1] Zhao Yongjuan, Pan Yutian, Huang Meixia Numerical Simulation of Chip Formation in Metal Cutting Process // TELKOMNIKA, Vol.10, No.3, September 2012, pp. 486 - 492.

[2] A. Muñoz-Sánchez, J.A. Canteli, J.L. Cantero, M.H. Miguélez, Numerical analysis of the tool wear effect in the machining induced residual stresses // Simulation Modelling Practice and Theory, 19, pp. $872-886,2011$.

[3] Hasan Gökkaya, The Effects of Machining Parameters on Cutting Forces, Surface Roughness, Built-Up Edge (BUE) and Built-Up Layer (BUL) During Machining AA2014 (T4) Alloy // Strojniški vestnik - Journal of Mechanical Engineering, 56(2010)9, pp. 584 593.

[4] C. Maranhão, J. Paulo Davim, Finite element modelling of machining of AISI 316 steel: Numerical simulation and experimental validation // Simulation Modelling Practice and Theory, 18, pp. $139-156,2010$.

[5] M. Sevier, H.T.Y. Yang, S. Lee and S. Chandrasekar Severe Plastic Deformation by Machining Characterized by Finite Element Simulation // METALLURGICAL AND MATERIALS TRANSACTIONS B, Vol. 38B, December 2007, pp.927-938

[6] Xuance Zhou, Qingshun Bai, Kai Yang, Zhi Luo, Relationship between Cutting Temperature and Cutting Parameters of Micromilling, // World Academy of Science, Engineering and Technology, 46, p. $568-571,2010$. 